\title{
Ontogeny of the Pain
}

\section{R. ROKYTA ${ }^{1}$, J. FRICOVÁ ${ }^{2}$}

${ }^{1}$ Department of Normal, Pathological and Clinical Physiology, Third Faculty of Medicine, Charles University, Prague, Czech Republic, ${ }^{2}$ Pain Management Center, First Faculty of Medicine and General University Hospital, Charles University, Prague, Czech Republic

Received April 2, 2012

Accepted May 29, 2012

\section{Summary}

The article gives an overview of developmental aspects of the ontogeny of pain both in experimental models and in children. The whole article is devoted to the ontogenesis in pain perception and the possible influence on it. The role of endogenous opioids on the development of pain and other important substances such as serotonin, nerve growth factor (NGF) and nicotine are mentioned. There are also important differences of the ontogenesis of thermal and mechanical nociceptive stimulation. The physiological and pathophysiological findings are the backgrounds for principles of treatment, taking into account the special status of analgesics during ontogeny. In particular there are mentioned the special effects of endogenous opioids and especially morphine. It describes the role of vitamin $\mathrm{D}$ and erythropoietin during the development of pain perception. This article also mentioned the critical developmental periods in relation to the perception of pain. The attention is paid to stress and immunological changes during the ontogeny of pain. Another important role is played by microglia. The work is concluded by some statements about the use of physiological and pathophysiological findings during the treatment of pain in pediatric practice. Codein analgesia is also described because codein starts to be very modern drug with the dependence.

\section{Key words}

Pain - Ontogeny - Pathophysiology • Clinical features • Treatment

\section{Corresponding author}

R. Rokyta, Department of Normal, Pathological and Clinical Physiology, Third Faculty of Medicine, Charles University in Prague, Ke Karlovu 4, 12000 Prague, Czech Republic. Tel/Fax: +420 224923 827. E-mail: richard.rokyta@If3.cuni.cz

\section{Introduction}

The intensive study of the physiology, pathophysiology, pharmacology and pain therapy denote the historical phases of medicine; however, the modern scientific study of pain began with the first description of the 'gate theory of pain' (Melzack and Wall 1965). Since then, the study of pain has become universal in scope and much better organized. In 1975, the International Association for the Study of Pain (IASP) was founded. Originally, it held plenary congresses every three years; however since 2010, after the Montreal meeting, the meeting interval was reduced to two years. This year marks the 14th World Congress, which will be held in Milan. In 1993 the Association of European chapters of IASP formed a federation, known as the European Federation of IASP Chapters (EFIC). It too was organized around congresses held every three years. Beginning in 2011 its organization structure was also changed to a two year cycle. The two groups currently have overlapping cycles so that every year there is a meeting of either the EFIC or IASP Congress. The ontogeny of pain has been feature of interest for many years, however it has been gaining attention, particularly over the last 25 years; and recently, the attention regarding the study of the ontogeny of pain has increased rather significantly. This is particularly important because research findings are widely applied in pediatric practice, which is different from how research findings enter clinical practice with adults. Children should never be thought of as miniature adults, either physically or mentally; they have qualitatively different characteristics, both mental and physical. Additionally, pain in children 
takes on a different character than that seen in adults, and requires unique and specific treatment methodologies. In the following review article we try to highlight the main aspects and the specific elements that are part of pain ontogeny.

\section{Ontogeny of pediatric pain}

Opinions on the pathophysiology of pediatric pain and pain in children have been clearly developed and stated in a variety of works (Fitzgerald 1991, Unruh 1992, McGrath and Unruh 2006). A starting point should be that the child perceives pain as effectively as an adult and the pain employees the same pathophysiological mechanisms (Fitzgerald and Anand 1993, Hoza 1995, Rokyta 1995, McGrath and Unruh 2006). Evidence of pain has been demonstrated even in the early prenatal period.

Like adults, pain can be divided into immediate pain that lasts from a few seconds to minutes, medium pain, which lasts from hours to days, and long-term pain that lasts from weeks to years. This division is responsible for the paralleling terms such as acute pain, chronic and recurrent pain. Chronic pain can be viewed as something similar to colic pain; however, in children this type of pain is uncommon.

Generally, pain can be thought of as a coin. One side is protective, i.e. it provides information about tissue injuries and potential malfunctions in the body. On the other side the nature of pain makes it burdensome and harmful. It is perhaps the second side of the pain coin that prompted it becoming a nosological entity. Pain perception has been demonstrated in the prenatal period, and of course, the existence of neonatal pain is obvious; both types have been demonstrated in many studies, both experimentally (Anand et al. 1987) and directly in children (Owens 1984, Fitzgerald 1991, Andrews and Fitzgerald 1994).

Fitzgerald (2005) declared that newborns have very strong pain behaviors, but its nature is not yet fully understood. The observation has historical roots in the fact that pain in newborns has often been undertreated. Pain in children uses the same functional signaling pathways that are found in the normal adult nervous system. In the first few postnatal weeks it appears as an organization of nociceptive circuits in the dorsal horns of the spinal cord. These circuits can be altered by both painful and painless sensory inputs in early postnatal life, although their mechanism is not yet fully known. Nonetheless, it is important for understanding pediatric pain and current research helps us to better define strategies for the treatment of postnatal pain in children.

In an editorial of the journal Pain, Fitzgerald and Walker (2009) discussed the situation through several meta-analysis studies. Children frequently receive trauma and tissue injuries during medical procedures, and repeated rescue procedures in intensive care units often cause local hyperalgesia in children. Pain has been shown to evoke specific brain activity in the cerebral cortex starting at 24 weeks of gestation. Of special concern is that this time period includes several critical developmental stages and plasticity of certain nociceptive circuits can create long-term changes. Early experiences with pain during these critical periods can be reflected in pain perception in adulthood. Therefore, the period at which pain exposure begins is very important.

Fitzgerald (2005) also described the role of early plasticity, which was reflected in the adult brain. She speculated as to whether pain is constant sensory modality and requires precise postnatal experience to create specific synaptic connections. Naturally, the developmental periods in which nociceptive patterns of behavior are formed are critically important. The pain is not like other sensory modalities, because the normal prenatal mammalian brain is not exposed to nociceptive inputs. Olfactory, auditory and tactile stimulation are developed immediately after the birth, and nociceptive afferent inputs are relatively inactive. This can be changed throughout life. Mammals are born with great potential to respond to painful stimuli. But these reflex pathways are poorly organized compared to adults. The first 10 days of life, about $70 \%$ of rat pups have the tailflick in the wrong direction during a painful stimulus to the tail. By 21 days postnatal, the reflex response has improved, but by less than $10 \%$. Such a change has been observed in the humans withdrawal reflex. Learning the withdrawal reflex does not affect its development. Normal development of tactile nociceptive circuits developed on the basis of tactile stimuli.

There are many experimental models that can be used to provoke it. Sensory nociceptive thresholds in children underwent early experiences with pain. A child can learn pain as a response to stressful situations. Since stress is ubiquitous, it can be associated with almost everything, which makes the stress-pain response difficult to differentiate.

The biggest problem of studies involving pain in young children is that, as in animals, we can observe only the behavioral aspects of pain. These allow us to study in 
detail only the painful process. They are primarily motor responses that begin with the diffuse motion of the body in children and even in preterm infants. The reaction is somewhat different than in adults, which is caused mainly by an incompletely myelinized nervous system. There are large differences in individual publications; some authors describe very significant motor changes (Sherman and Sherman 1925, Dockeray and Rice 1934), while the others do not (McGraw 1941). The motor response to a pinch on the leg proceeds with flexion and adduction of the upper and lower extremities, and is often accompanied by changes in facial expression or crying.

\section{The special features of pain in children}

It is important to realize that the free nerve endings are already present in the fetal and neonatal skin, just as it is in adult skin. An important indicator of pain is the change in facial expression, very young children are able to express various subjective feelings through changes in their facial expressions e.g. joy, sadness, surprise, and pain. There is a latency of facial expression provoked by painful stimulation in children (Slater et al. 2010). It depends on gestational age. Facial expressions are fixed to painful stimulation and must be considered in the calculation in pain scores in premature and normal newborns. It is important to use it when assessing the behavior of newborns.

Children can express pain in a variety of ways. Another indicator is crying. Crying is basic communication and is caused by stimuli other than pain. There is a spectrum of different types of cries and harsh vocalizations, which can express things like pain, hunger and/or fear. These sounds have been studied using spectroscopy analysis (Wasz-Hockert et al. 1968, 1985, Johnson et al. 1993) and spectrographic differences were found in the cry in full-term newborns and premature babies. These sounds were also studied experimentally during circumcision (Williamson and Williamson 1983). Newborns have more emotions and are more sensitive to pain than older children aged 3-12 months. Latency responses between fetal and neonatal subjects are similar. From a behavioral point of view it is necessary to study the entire complex of motor responses, including changes in facial expression and crying. All behavioral studies have shown that the pathophysiological mechanisms, which have been studied mainly in animals, are very similar to the mechanisms found in adults (Johnson and Spence 1994, Johnson et al. 1994, Tseng et al. 1995).
Growth pains in children are located in the lower extremities. It often awakens the child from sleep, and seems most prevalent in the evening and nighttime hours. Growth pain affects children aged 3 to 12 years of age and occurs in $2-50 \%$ of children. The cause of this pain is not known, and there is no organic disease associated with growth pains. In many cases the diagnosis is often clear. Although the pain is termed growth pain, there appears to be no link to growth in children (Arikka 2010).

\section{The transmission of pain in ontogeny}

The conduction of nociceptive information from nocisensors is effectuated by $\mathrm{A} \delta$ (A delta) and C fibers, which are already developed by late fetal life. At birth, the peripheral receptors are very similar to the nocisensors of adults. Nocisensors are developed very early in ontogeny. A $\delta$ fibers (partly myelinized) evolve much faster than $\mathrm{C}$ fibers. The fibers begin to appear in the first postnatal week. We can state that during early ontogeny there is a redistribution of painful stimuli lead by $\mathrm{C}$ fibers and $\mathrm{A} \delta$ fibers. In summary: two different impulses running along myelinized $\mathrm{A} \delta$ nerve fibers, leading sharp and acute pain, and non-myelinized pain $\mathrm{C}$ fibers which lead a dull, chronic and very unpleasant pain. Generally this information is kept separated and moves together in nerve bundles containing both $\mathrm{A} \delta$ and $\mathrm{C}$ fibers and runs along peripheral nerves to the spinal cord. Receptive pain fields in newborns period are quite large and have a longer latency responses. The $\mathrm{A} \delta$ and $\mathrm{C}$ fibers carry information into the dorsal horns of the spinal cord (substantia gelatinosa Rolandi and posteriolateral tract (Lissauer tract). Bremner and Fitzgerald (2008) described postnatal changes in the cutaneous inhibitory receptive fields in rats. Contralateral inhibition of the spinal dorsal horn was already present by the third postnatal day. Inhibitory receptive fields were less restricted on the third postnatal day than in adulthood. The intensity of inhibition of receptive fields was less accentuated in newborns. Significant postnatal changes in image inhibition contribute to the maturation of tactile and nociceptive spinal processes and coordinates sensorimotor and pain behavior in adults.

\section{Enkephalins, endorphins and opioids during the development}

It seems that the role of enkephalins and modulation of endorphins do not function in newborns at 
adult levels, although they exists soon after birth (Fitzgerald and Koltzenburg 1986). Therefore, premature infants and newborns in this respect could have more intensive pain than adults. A comparison is very difficult mainly because the only information available is behavioral. Pain appears to be modulated in similar way in both children and adults. Apart from the modulatory substances mentioned above, there is another compound, serotonin, which is released during tissue trauma. Serotonin, however, is produced mainly in the dorsal raphe nucleus in the midbrain and hypothalamus. This has particular significance relative to severe headaches that can occur in children. Serotonin also appears to be able to modulate circadian cycles.

Joseph et al. (2011) stated that mechanical hyperalgesia can be caused by increased stimulation of endothelin-1. In addition to endothelin-1, there are several other factors that are directly activated by hyperalgesia including prostaglandin $E_{2}$, nerve gliaderived neurotrophic/nerve growth factor (NGF), interleukin 6 and tumor necrosis factor alpha (TNF- $\alpha$ ). They can lead to a huge mechanical hyperalgesia; no other similar mechanical stimulation causes this type of extreme hyperalgesia.

Enkephalins are predominantly active at opioid receptors. During modeling of the pain the attention should also be given to genetic and tribal differences. Large differences have been observed between Wistar, Long-Evans and SHR rats (Hassmannová and Rokyta 2002, Rokyta et al. 2006). Naloxone, which is a selective inhibitor of beta-endorphins, starts its effect on the 20th postnatal day. In animal models, the weaning period is important because in that time the response to pain is changing, particularly in terms of affective emotional components of pain. Pain that occurs during development also affects the hormonal situation. Animal experiments have shown that morphine, at a dose of $1 \mathrm{mg} / \mathrm{kg}$, significantly increased analgesia in castrated male rats (Islam et al. 1993). Pain threshold changes in rats have been shown to take place between the 10th to 45th day of age (Ba and Seri 1993, Pujol et al. 1993). To illustrate, the mean tail-flick latency declines from the 10th to 25 th day and then remained stable through the 45 th day. If we compared the motor response threshold to painful stimulation (electrical stimulation of the tail), using the tail-flick stimulus, vocalizations during and subsequent vocalizations, we found that older adult animals had significantly higher thresholds, when compared to newborns. The weaning period is critical for the development of mechanisms that lead to emotionally affective component of pain (Viveros et al. 1993).

\section{Consequences of pain on the different system of the body}

These are mainly changes in the cardiovascular system and blood oxygen saturation. Painful stimulation generally decreases the transcutaneous partial pressure of oxygen. This fact could be responsible for the more difficult administration of local anesthetics (Williamson and Williamson 1983). Similarly, other painful manipulation reduces the total partial pressure of oxygen. It was observed especially during circumcision, when the pain increased heart rate and blood pressure mainly due to the sympathetic activation. Interestingly, the increase in blood pressure and heart rate is directly proportional to the intensity of stimulation. After applying any antianalgesic agents, the cardiovascular responses are reduced. This reduction can be induce by many factors, including stress, administration of opioids, and betaadrenergic blockade; i.e. by everything that lowers sympathetic activity. Opioids generally increase the parasympathetic influence.

In addition to the known substances that are responsible for pain, we have also consider plasma renin activity. This is particularly important relative to venipunctures, which is a moderate pain stimulus. When you perform venipuncture, there are no changes in the levels of cortisol, adrenaline and noradrenaline, but they are changes in plasma renin levels. During more traumatic procedures (e.g. endotracheal suction) there are increased levels of catecholamines, but they immediately go down following the administration of sedation. Immunological indicators have a very important relationship to pain, the term for this is specialized psychoneuroendocrine immunology and it can affect many immunological functions (Yaster 2010).

From a developmental perspective it is also important to note that changes in pain perception and expression are found not only in children, but they are found throughout the whole life, and even in old age (Corran et al. 1994). For example, there is a greater sensitivity of old rats to the anxiety-generating effects in the maze.

In the study of Johnson et al. (1993) the children were exposed to pain: 1) premature infants between 30-34 gestational weeks were painfully stimulated with a pin prick in the ankle; 2) term newborn infants received vitamin $\mathrm{K}$ injections; 3 ) two-month-old children received 
subcutaneous immunization injections, and (4) fourmonth-old children were given subcutaneous injections for immunization. This study was designed to evaluate crying and the NFCS (Neonatal Facial Action Coding System). Multivariate analysis showed that premature infants had different reactions compared to adults (Johnson et al. 1993). Children born at term differed from all other groups (two- and four-month-old children had the same reaction). Especially the differences were found in a more intense cry of these premature babies. Their reactions are not yet well developed and children born at term are better equipped to interact with facial reactions. Cries of preterm infants are quite different than vocalizations in term infants (Friedman et al. 1982, Wasz-Hockert et al. 1985, Akanne and Soliman 1994).

\section{Serotonin and NGF activity during development}

Older animals are less sensitive to pain than younger animals (e.g. in the tail-flick test, hot-plate $55^{\circ} \mathrm{C}$, hind limbs immersion test). These changes in children follow the circadian rhythm. The longest latency is during the darkness and the shortest latency occurs during the light period (Islam et al. 1993).

Metasergit, a serotonin antagonist, evoked hyperalgesia in both groups of animals. The serotonergic system modulates the sensitivity of old and young animals, but the reactions are different, with age increases producing a decreased response to application of spinal opioids. Perhaps this is because the aging process reduces the ability of opioid receptors to mediate antinociception (Fried 1992, Neisewander et al. 1994, Krakowski et al. 1996).

Growth factors play a special role in the modulation of pain in children, especially the nerve growth factor (NGF). Peripheral nerve growth is not possible without NGF which is particularly important for the development of nociceptive A $\delta$ fibers. Whether it also affects the growth of $\mathrm{C}$ fibers is still unknown. Newborn rats, which were treated postnatally with NGF antibodies, have a lower number of $\mathrm{C}$ fibers. It seems, therefore, that NGF is important also for C fibers development (Lewin and Mendell 1994).

\section{The ontogeny of the different thermal and mechanical nociceptive stimulation}

Experiments in rats (Ba and Seri 1993, Tseng et al. 1995) showed that thermal nociceptive predictions triggered by beta-endorphin and morphine develops between postnatal days 7-14 and continues until the postnatal days 21-28. Mechanical responses to pain induced by beta-endorphin are already present on postnatal day 2 and for morphine it is present by postnatal day 4. Mechanical antinociception progressively increases and reaches a plateau on postnatal day 7 for beta endorphins and on postnatal day 28 for morphine. The effect of beta endorphin is far more effective than morphine for mechanical antinociception. Development on mechanical and thermal nociception is completely different. Thus is probably due to the fact that there exist two inhibitory systems, both of which activate beta endorphins and morphine, but their development is different (Rajevská et al. 1990).

\section{Pain threshold during development}

There was a correlation between post-conception time and pain threshold. In the 29th week, the mechanical threshold is at $0.237 \mathrm{~g}$ while in the 41 st week the values have fallen to $0.980 \mathrm{~g}$. Repeated stimulation leads to a reduction in the thresholds (sensitization) up to the 35 th week of life. Thereafter no changes in threshold but a certain degree of habituation were observed. From the 27 th post-conception week it was possible to elicit reflexes on the surfaces of the legs, thighs and hips. To the 30th post-conception week the threshold of receptive fields was the same, but after the 30th week it was possible to observe a gradient that progressively increased from the soles of the feet to the knees.

\section{Analgesics and treatment during the pain ontogeny}

When is an analgesic an analgesic? Analgesics may not always relieve pain, because in some situations, some analgesics act early-on in life as analgesics and later in life has non-analgesic effect (Fitzgerald 2005).

In children the multimodal analgesia has been often used (Yaster 2010). The administration of multimodal analgesia has essentially the purpose of preventive analgesia both opioid and non-opioid. NSAIDs, local anesthetics, NMDA antagonists, $\alpha_{2}$-adrenergic agents can also be used. They can be administered alone or in combination with opioids to maximize pain control and minimize the side effects of these drugs. A multimodal approach can also be used 
with non-pharmacological complementary or alternative medical methods. These techniques include controlled imagination, hypnosis, relaxation techniques, biofeeback, TENS (transcutaneous electrical nervous stimulation) and acupuncture.

\section{Newborns after the delivery in epidural anesthesia}

Epidural anesthesia reduces the duration of labor, has no adverse effects on the newborn and hypoxic encephalopathy is rare. Anesthesia is fine at birth and is also used (perhaps more frequently) during vacuum extraction. Epidural anesthesia does not increase the degree of neonatal injury (Johnsrud et al. 1988).

Epidural anesthesia was studied in young animals especially with the respect to the effects of carrageenan and capsaicin (Marsh et al. 1999). Newborn rats can develop allodynia and hyperalgesia after experimental inflammation, which is blocked by epidural administration of mu, delta and kappa opioids.

Sanchez-Simon et al. (2010) studied the effect of morphine in vivo on neuronal fate and expression of opioid receptors. Morphine remains one of the most effective analgesic drugs despite its well known negative effects. It binds to opioid receptors, mu, delta and kappa. These receptors are important for neuronal properties such as cell proliferation, neuroprotection and neuronal differentiation. In vitro studies on the effects of morphine have been controversial. In vivo studies in adult and neonatal mammalian models have not been able completely elucidate the roles of morphine in the CNS.

\section{The effect of morphine during the ontogeny of pain}

In the embryos of zebra fish we have observed (Sanches-Simons et al. 2010) that at 24-48 hours after fertilization, morphine enhances cell proliferation, but has the opposite effect at the beginning of neuronal differentiation. After its application the neuronal population is increased after 24 hours, but decreased after 48 hours. Morphine gives the embryo a 24-hour neuroprotective effect against glutamate damage to motor neurons. Gene expression of opioid receptors alternates. Morphine has a dual in vivo effect. First, it is important for cell proliferation and cell protection and it may be associated with gene expression of opioid receptors. Gao et al. (2010) reported growth retardation in a child with
Crohn's disease. Immunosuppressive therapy may improve the prognosis of this disease; however, it is very important to monitor the disease because early treatment is more effective.

Endogenous opioid morphine prevents neural stem cells proliferation (Shoae-Hassani et al. 2011). Morphine reduces testosterone levels and overexpression of the gene E53. Therefore, morphine may prevent the proliferation of neural stem cells.

\section{Glutamatergic, gabaergic and dopaminergic effects on the development of pain}

Buspirone administration protects against the harmful effects of stress in the uterus and painful emotional behavior and offspring. Buspirone is an antianxiety agent. Stressed males have now weight gain as a side effect of treatment with antidepressants (Butkevich et al. 2011). Glutamatergic, GABAergic, dopaminergic but not cholinergic neurons are responsible for the induction of cell death in the developing rat brain. In clinical trials (Fitzgerald 1991) neuronal cell death was caused by anesthetic agents, but the reason was not clear. Sprague-Dawley rats were studied for 7 days. They were divided into two groups: naive, and with anesthetics (its composition was nitric oxide and $2.5 \%$ isoflurane, the exposure lasted 6 hours). After histological procedures the brains were studied, especially the basal forebrain, substantia nigra, cornu Ammonis, cingulate gyrus and hippocampal subareas. Anesthetics significantly increase neuroapoptosis of glutamatergic, GABAergic and dopaminergic neurons in the developing brains. Barr (2011) reported that formalin-induced c-Fos expression exists in the brains of adolescent rats aged 3-14 days. Protein staining was significantly increased in ventrolateral medulla, whereas in the thalamus, the periventricular hypothalamic nucleus and periaqueductal gray c-Fos protein levels were elevated only after the 14th day. The development pattern is related not only to the maturation of pain perception, but also to the development of the autonomic nervous system and to the defensive reaction to pain in young animals. Painful procedures are different in neonates, children and adults. It is possible to apply these findings in pediatric clinical practice. The brain response to pain is immature at birth but begins to appear after the 14th day of life. 


\section{The neurobehavioral development of pain perception}

Lester et al. (2011) and Gurd (2011) described pain in young athletes, which is a very common finding. There are several things that can cause pain in active children and a diagnosis depends on a thorough physical and radiological examination. Early treatment helps to prevent recurrences or exacerbations of this phenomenon. Low vitamin D levels play an important role in growth pain. For all children with unexplained limb pain without an identified organic pathology should have their vitamin D status evaluated and treated as necessary. Hypovitaminosis D is common among young girls (59\%) aged 8 years. Only $6 \%$ had normal levels of vitamin D, $94 \%$ had a vitamin D deficiency; despite this, they had normal alkaline phosphatase and normal levels of parathyroid hormone. Hypovitaminosis D causes muscle hypersensitivity and sensory hyperinnervation. Additionally, a vitamin D deficit can result in selective alteration of target innervation and hyperinnervation of nocisensors in skeletal muscle tissue. All of these factors can contribute to muscle pain and hypersensitivity.

Clarke and Page (2012) studied vitamin D deficiency from a pediatric-orthopedic perspective. Vitamin D is a key element in a successful practice of pediatric orthopedics. This is very important not only in terms of normal development, but also in terms of postoperative pain and the patient's return to a condition without pain. Lima et al. (2011) and Hirsch et al. (2012) carried out epidemiological studies on symptoms linked to temporo-mandibular joint syndrome and its relation to pubertal development in adolescents. The syndrome is more common in girls and clinical diagnosis is relatively straightforward. Pubertal development increases the probability of this syndrome among girls and decreases it among boys. It is well established that the phenomenon exists not only in adulthood, but also in adolescence.

\section{Erythropoietin}

Mohamad et al. (2011) suggest that erythropoietin reduces neuronal cell death and hyperalgesia caused by peripheral inflammatory pain in neonatal rats. It is interesting that erythropoietin protects against the pain. Three-day-old rats received injections of formalin for three days. After 21 days they received a different nociceptive stimulus, which lead to increased local cerebral blood flow, but reduced exploratory behavior linked to the somatosensory cortex. The administration of recombinant human erythropoietin as an anti-inflammatory agent was shown to be protective. Animals that received formalin and erythropoietin still had normal levels of cerebral blood flow, normal sensitivity to pain and retained normal exploratory behavior. Treatment with erythropoietin improved brain perfusion and increased body weight which tended to be the decreased in the formalin group. Severe inflammatory pain has adverse effects on brain development. On the other hand, the administration of erythropoietin could be a possible approach to the treatment and prevention of developmental changes associated with pain.

\section{Low and neck back pain during development}

Young and d'Hemecourt (2011) describe the back pain in adolescent athletes. Back pains in pediatrics and adolescent populations are different from those in adults because they have open epiphyses and linear growth rates are increased. Injuries often depend how children practice sports, but more sports signal more risk of injury. Back pain can threaten the development and growth of the pelvis and spine.

Kubo et al. (2012) described the absence of mechanical hyperalgesia after the exercise in rats receiving neonatal capsaicin. $\mathrm{C}$ fibers appear to be crucial for the transmission of nociceptive information from exercising muscles. Hyperalgesia is associated with other substances in muscle, especially with nervous growth factor, which causes mechanical hyperalgesia. It was also increased in rats receiving capsaicin.

\section{Stress, imunological changes, critical periods and models of pain in ontogeny}

Butkevich and Vershinina (2003) studied the long-term effects of prenatal stress (immobilization stress of rat dams during the last week of pregnancy). The sensitivity to pain is changing in rats during the prepuberty and puberty, throughout the whole development and even in adulthood. Pain sensitivity was tested using the formalin test and behavioral testing. The response to prenatal stress depends if it was focused on the spinal or supraspinal level. It was also different between females and males. Further studies aimed to isolate different periods of prenatal stress. The consequences of prenatal stress on the spinal level were manifested as descending modulating activation of 
facilitation and suppression of the monoaminergic inhibitory system in the prepubertal and pubertal periods. In contrast, the activation of descending inhibitory system and the suppression of facilitation system was manifested in adults after the stress influence. During the development, many systems participate in pain management processes.

Houfflin Debarge et al. (2005) developed a new model for studying fetal nociceptive pathways in fetal sheep. Electromyographic responses were registered from the $\mathrm{m}$. biceps femoris in response to electrical stimulation of the sural nerve while the fetus was under the influence of sufentanil. EMG responses could be registered after $140 \mathrm{~ms}$ of super-threshold electrical stimulation; and resulted in a nociceptive flexion reflex. Reflexes increased with stimulus intensity and sufentanil decreased this response. Bradycardia was recorded $10 \mathrm{~s}$ after stimulation and was also observed after the sufentanil infusion. The degree of catecholamine stimulation was not changed. The nociceptive flexion reflex can also be observed in the bovine fetus. This reflex can be used as a new tool in the study of the ontogeny of nociceptive pathways and analgesic effects during fetal life.

Hathway et al. (2012) describe critical periods in the supraspinal pain control. They are opioid-dependent changes in the brain stem in the rostroventral medulla (RVM) in preadolescence which can be illustrated (using electromyography) by the application of gly-enkephalin (DAMGO) into the RVM of lightly anesthetized animals. It causes a weight-dependent reduction of the mechanical nociceptive reflex of hind limbs in preadolescent rats (postnatal day 21). Even after fully maturing, the same dose of gly-enkephalin causes reflex facilitation. When injected into the RVM (rostroventromedial medulla), kappa opioid receptor agonist or $\mathrm{GABA}_{\mathrm{A}}$ receptor agonist cause depression of this reflex in both age groups. There is descending facilitation of spinal nociception in young animals and it is mediated by the $\eta$ opioid receptors in the RVM pathways. Developmental transition from facilitation to inhibition of pain is determined by the activity of central opioid pathways during the critical periods of preadolescence - see papers about changing GABA activity in the early stages of life (Rokyta et al. 1963, Mysliveček et al. 1965, Ben-Ari et al. 2001). In the early stages of life GABA has an excitatory effect which becomes inhibitory later on.

Beggs et al. (2012) describe an increased neuroimmunological response in neonatal animals, which can be demonstrated using direct electrical stimulation of the tibial nerve. There is a central mechanism that supports this long-lasting effect; it is present from an early stage and after injury, it may predispose individuals to increased sensitivity to pain later in life.

Fabrizi et al. (2011) described specific neural circuits in the human brain that were necessary for discrimination between touch and nociception were present and clearly defined at 35-37 weeks of gestation.

Oral glucose is sometimes regarded as analgesic substance in procedural pain in neonates (Slater et al. 2010). In this study oral glucose had no significant effect on the neonatal brain or spinal cord circuits. Therefore, it cannot be an effective analgesic agent. The ability of sucrose to reduce clinical scores relative to painful situations in neonates cannot be interpreted as a reduction of the pain, rather it is the psychological effect of something sweet.

Slater et al. (2010) announced that preterm babies had increased pain which evoked neuronal activity in the brain, compared to healthy individuals born at the same time. Neuroimmune interaction that follows peripheral nerve injury has substantial adaptive immune component, which is absent in immature central nervous system. It is the infiltration of $\mathrm{T}$ cells, which then signal changes in the adult spinal cord. They are the main contributor to the development of neuropathic pain hypersensitivity and its components (Costigan et al. 2009).

Early pain (Walker et al. 2009b) caused by an incision in early life, evoked a hyperalgesic response to repeated surgery. It is important to note again, that the original trauma occurred during a critical developmental period. The incision was done between postnatal days 3-6 and hyperalgesia occurred two weeks later. The hyperalgesic response was two times stronger than in animals in which the simple incision occurred outside of the critical period. If the incisions were done on the 10th, 21 st and 40th day, they produced similar results. The first postnatal week in rats represents a critical period for the development of incisional hyperalgesia. This effect is initiated by increased activity of peripheral afferent fibers. This finding has potential therapeutic implication for thermic perioperative analgesia, which is used in neonatal surgery.

Brain in the newborn child is capable to provide sensory discrimination of pain experience (Slater et al. 2010). In the pain management of children's it is necessary to select the neurobiological development approach. Untreated pain in childhood results in adverse 
consequences in adulthood; therefore, pain should be treated as soon as possible in children (Fitzgerald and Walker 2009). Walker et al. (2009a) observed the longterm impact of neonatal intensive pain and surgery on somatosensory perception in children who are born extremely prematurely. Children, who were born in the 26th week, had some reduction in specific processes such as mechanical and thermal sensitivity, which causes localized tissue damage. Generalize reduction in thermal sensitivity (but not mechanical) is a centrally mediated alteration and modulation of nociceptive $\mathrm{C}$ fibers. This may affect the response to pain caused by a subsequent surgery. $\mathrm{C}$ fibers appear to play a crucial role in these early development periods.

\section{The changes related to the microglia in the spinal cord}

This is an astrocyte response to nerve damage (Vega-Avalaira et al. 2007). Nerve damage in young animals evokes a very robust response from astrocytes in the first day after birth, which has not been observed in adults. Further activation is also seen on the 7 th postnatal day. The development of different glial responses to nerve damage, may explain why neuropathic allodynia is not found in young animals (Moss et al. 2007).

\section{Further important findings}

Fitzgerald (2005) described the development of pain circuits that depended on painful sensory activity in healthy newborns. It explains how early painful injury can permanently alter development processes.

Howard et al. (2005) followed the ontogeny of neuropathic pain in the SNI model (spared nervous injury) and chronic constriction injury; both are wellknown experimental models. Mechanical allodynia can be evoked in very young animals with inflammatory pain. The developmental profile is selective for peripheral neuropathic pain and shows the remarkable ability of young animals to compensate for the effects of sensory nerve damage. The results are consistent with human responses to pain from nerve damage and are very similar. The SNI evokes neuropathic pain, while chronic constriction injury on the 10th day of life provokes clear allodynia in adulthood.

The potency of opioids is increased compared with antinociceptive acute tests. Capsaicin hyperalgesia was also observed. C fibers increased central excitability, but are under the influence of special mechanisms associated with inflammatory pain. In the dorsal horn was observed afferent terminal plasticity, which was affected by neonatal inflammation. The duration and effect of neonatal inflammation depends on the type and amount of inflammatory agents used. Inflammation after the administration of Freund's adjuvant resulted in the expansion of afferent terminals in spinal cord (lamina 2; substantia gelatinosa Rolandi), which continued into adulthood. This effect was not observed in adult animals. Plasticity is known to exist in early periods of life. Freund's adjuvant induced plasticity even in these very early periods of life. c-Fos immunoreactivity in the dorsal horns of the spinal cord can be induced in the neonatal spinal cord by both painful and painless peripheral stimulation to an equal extent. Primary and secondary hyperalgesia may be different at different postnatal periods. Studies have been conducted the examined the effects at postnatal days (PD) 3, 10 and 21. Primary hyperalgesia can be evoked on PD 3, but it was clearly evident only on PD 10 and PD 21. Primary and secondary hyperalgesia are modulated differently during the development; however, the important point is that it is possible to trigger primary hyperalgesia on postnatal day 3 (Walker et al. 2009b).

Evoked potentials in the human brain can be caused by painful stimulation and this potential seems to be present in newborn children between 30 and 39 gestational weeks. All components up to $560 \mathrm{~ms}$ are present and their size does not depend on the state of sleep, but the early potentials do (Slater et al. 2010). Electrical activity is evoked by both painful and painless stimuli. The first pain-evoked neuronal activity in a child brain is very specific and starts early in life. Newborns can determine the sensory-discriminatory aspects of pain experiences (Moss et al. 2007). Low-frequency stimulation of peripheral $\mathrm{C}$ fibers evokes prolonged microglial-induced central sensitization in adult animals but not in neonates (Hathway et al. 2009).

\section{Several remarks about special treatment of pain in ontogeny and pediatric care}

Oral sucrose is used in children and its psychological effects as an antidepressant often manifest as analgesic effects on pain mechanisms (Slater et al. 2010). Delta and mu opioid receptors have been shown to downregulate variably in primary sensory nerves during postnatal development in rats. Opioid analgesia affects 
the reflex response to painful stimuli in rats. Fabrizi et al. (2011) revealed a shift of sensory processes based on the fact that young brains are not able to distinguish pain from touch, but distinction develops between 28-40 weeks of gestation. The first discrimination in the human brain begins promptly at the age of about 35-37 weeks.

Koch et al. (2008) described the opposite effects of midazolam on nociception and sedation in rats aged 3 and 10 days. Midazolam at this age has a sedative effect while sensitizing flexor reflex activity. The sedative effect of midazolam was not observed until maturation of supraspinal center. There is a need to better understand the pharmacology of substances that are used in prenatal intensive care.

Alcantara and Davis (2011) described the chiropractic care of pediatric patients who complained of growth pain. They reported on two patients who were repeatedly awakened by nocturnal pain. Manipulation of the spine was very effective and was able to eliminate the pathological effects. Chiropractic spinal manipulative therapy needs to be explored as a possible treatment for children who complain with growth pains.

Hopchet et al. (2011) used intravenous paracetamol (acetaminophen) in neonates with a mean weight of $2.7 \mathrm{~kg}$ and mean gestational age 37 weeks (range 27-50 weeks). They studied normal term neonates and six infants which had a fever. Acetaminophen had already the protective effect on the pain in preterm newborns and did not affect the temperature of normothermic neonates, while in the neonates with fever, it produced a dramatic decline in the first 2 hours and was followed by further standardization. Application of intravenous paracetamol does not cause hypothermia in normal term neonates, but for those with a fever, fever reduction is achieved within 2 hours of administration. This thermal changes are important for the application for acetaminophen (paracetamol) in early ontogeny.

\section{Developmental regulation of codeine analgesia in rats}

Codeine analgesia is developmentally regulated with a very low efficiency in the early postnatal period. Effect in adult rats was not predictive for efficacy in any particular strain (Sprague-Dawley, Dark Agooti), which has an important implication for further studies and possibly even for clinical use. Developmental changes played no significant role. Analgesia, which is caused by stress during ontogeny, already exists by the third postnatal day. This analgesia, which increases in strength and duration up to postnatal days $17-20$, increases the descendent supraspinal inhibition. It is known that mechanisms of nociception are present both prenatally and postnatally, but the nociception develops gradually after birth, whereas the preterm birth greatly retards this process (Williams et al. 2004). Evidence for this is seen in the experiments (Rossitch et al. 1992, Viveros et al. 1993), which showed that neonate rats have much more pronounced behavioral signs of mechanical allodynia and pain than adult rats. Tanck et al. (1992) showed that younger rats have far more robust behavioral signs of neuropathic pain than older individuals. In experiments with humans (150 volunteers, aged 10-73 years) concerning specific thermal thresholds, no major developmental changes were found. However, there were large differences between sex, with women showing greater sensitivity to small changes in temperature, but not finding significant changes in temperature to be painful (Viveros et al. 1993). Newborn rats were more sensitive to antinociceptive agents in phasic nociceptive tests. Rats, which were born to dams treated with nicotine during pregnancy, extended nicotine-induced analgesia to adulthood (Zbuzek and Chin 1994). The aging process clearly impairs inhibitory functions and the amount of $\delta$-opioid receptors in rat spinal cord.

Andrews and Fitzgerald (1994) assessed the sensitivity of injuries as a measure of analgesic effects following surgery in newborns and children by measuring objectively and quantitatively the development of sensitivity to pain and wounds and analgesia in children following the surgery. The reflex threshold can quantify the human central sensory processes and can be used as a reference point for visceral hypersensitivity in different age groups. Children, who were born prematurely and had experience with 40 days of intensive or special care, had increased cerebral neuronal responses to noxious stimuli compared to healthy newborns. Our ability to quantify the changes in the brain of children, which are dependent on the experience, suggests the need for a rational approach regarding pain management in neonatal intensive care. Medical care must be used carefully and appropriately, with a full recognition that neonates and even preterm infants experience pain as well as the physiological stress responses that typically accompany pain.

\section{Conclusions}

This synoptic work discussed the important 
developmental aspects of pain perception, including the role of developmental periods. Major differences in physiology and pathophysiology of pain have been reported in both experimental animals and in children. The description begins with the prenatal period, continues through early postnatal period and ends in adolescence. The paper also mentioned some important substances that affect pain perception in ontogeny. It concerns the body own substances and also exogenous substances which are injected into the body. These are endogenous and exogenous opioids, and some scavengers such as erythropoietin. Experimental findings are confronted with the practical advantage in pediatric practice during the treatment of pain syndromes in newborns, infants and adolescents. We believe that this article will be of benefit for those who want to use these findings in pediatric practice, especially for fighting with chronic pain.

\section{Conflict of Interest}

There is no conflict of interest.

\section{Acknowledgement}

The paper was supported by the grant PRVOUK P34.

\section{References}

AKANNE HC, SOLIMAN KF: Serotonin modulation of pain responsiveness in the aged rat. Pharmacol Biochem Behav 48: 411-416, 1994.

ALCANTARA J, DAVIS J: The chiropractic care of children with „growing pains“: a case series and systematic review of the literature. Complement Ther Clin Pract 17: 28-32, 2011.

ANAND KJ, SIPPELL SWG, AYNSLEY-GREEN A: Randomized trial of fentanyl anaesthesia in preterm babies undergoing surgery, effects on the stress response. Lancet 1: 243-248, 1987.

ANDREWS K, FITZGERALD M: The cutaneous withdrawal reflex in human neonates: sensitization, receptive fields, and the effects of contralateral stimulation. Pain 56: 95-101, 1994.

ARIKKA H: Growing pains in children. Duodecim 126: 1895-1901, 2010.

BA A, SERI BV: Functional development of central nervous system in the rat: ontogeny of nociceptive thresholds. Physiol Behav 54: 403-405, 1993.

BARR GA: Formalin-induced c-fos expression in the brain of infant rats. J Pain 12: 263-271, 2011.

BEN-ARI Y, KHAZIPOV R, LEINEKUGEL X, CAILLARD O, GAIARSA JL: GABA $A_{A}$, NMDA and AMPA receptors. Trends Neurosci 24: 353-360, 2001.

BEGGS S, CURRIE G, SALTER MW, FITZGERALD M, WALKER SM: Priming of adult pain responses by neonatal pain experience: maintenance by central neuroimmune activity. Brain 135: 404-417, 2012.

BREMNER LR, FITZGERALD M: Postnatal tuning of cutaneous inhibitory receptive fields in the rat. $J$ Physiol Lond 586: 1529-1537, 2008.

BUTKEVICH I, VERSHININA E: Maternal stress differently alters nociceptive behaviors in the formalin test in adult female and male rats. Brain Res 961: 159-165, 2003.

BUTKEVICH I, MIKHAILENKO V, VERSHININA E, SEMIONOV P, MAKUKHINA G, OTELLIN V: Maternal buspirone protects against the adverse effects of in utero stress on emotional and pain-related behaviors in offspring. Physiol Behav 102: 137-142, 2011.

CLARKE NM, PAGE JE: Vitamin D deficiency: a paediatric orthopaedic perspective. Curr Opin Pediatr 24: 46-49, 2012.

CORRAN TM, GIBSON SJ, FARRELL MJ, HELME RD: Comparison of chronic pain experience between young and elderly patients. Proc 7th World Congress on Pain, 1994, pp 895-906.

COSTIGAN M, SCHOLZ J, WOOLF CJ: Neuropathic pain: a maladaptive response of the nervous system to damage. Annu Rev Neurosci 32: 1-32, 2009.

DOCKERAY FC, RICE C: Responses of newborn infants to pain stimulation. Physiology 12: 82-93, 1934.

FABRIZI L, SLATER R, WORLEY A, MEEK J, BOYD S, OLHEDE S, FITZGERALD M: Shift in sensory processing that enables the developing human brain to discriminate touch from pain. Curr Biol 21: 1552-1558, 2011. 
FITZGERALD M: The developmental neurobiology of pain. In: Pain Research and Clinical Management Vol. 4, MR BOND, JE CHARLTON, CJ WOOLF (eds), Elsevier, Amsterdam, 1991, pp 253-262.

FITZGERALD M: The development of nociceptive circuits. Nat Rev Neurosci 6: 507-520, 2005.

FITZGERALD M, ANAND KJS: Developmental neuroanatomy and neurophysiology of pain. In: Pain in Infants, Children and Adolescents. NL SCHECHTER, CB BERDE, M YASTER (eds), Williams \& Wilkins, Baltimore, 1993, pp 11-31.

FITZGERALD M, KOLTZENBURG M: The functional development of descending inhibitory pathways in the dorsolateral funiculus of the newborn rat spinal cord. Dev Brain Res 24: 261-270, 1986.

FITZGERALD M, WALKER SM: Infant pain management: a developmental neurobiological approach. Nat Clin Pract Neurol 5: 35-50, 2009.

FRIED K: Changes in pulpal nerves with aging. Proc Finn Dent Soc 88 (Suppl 1): 517-528, 1992.

FRIEDMAN SL, ZAHN-WAXLER C, RADKE-YARROW M: Perceptions of cries of full-term and preterm infants. Behav Dev 5: 161-173, 1982.

GAO X, SHEN ZY, CHEN MH, XIAO YL, YANG RP, HU PJ: Over one year follow-up report for newly diagnosed pediatric Crohn's Disease (in Chinese). Zhonghua Yi Xue Za Zhi 90: 1113-1116, 2010.

GURD DP: Back pain in the young athlete. Sports Med Arthrosc 19: 7-16, 2011.

HASSMANNOVÁ J, ROKYTA R: Chronic pain stimulation in rat ontogeny Dolor Suppl I: 31, 1997.

HASSMANNOVÁ J, ROKYTA R: The postnatal development of tail-flick latencies to acute and repeated stimulation in the rat. Exp Physiol 87: 63-67, 2002.

HATHWAY GJ, VEGA-AVELAIRA D, MOSS A, INGRAM R, FITZGERALD M: Brief, low frequency stimulation of rat peripheral C-fibres evokes prolonged microglial-induced central sensitization in adults but not in neonates. Pain 144: 110-118, 2009.

HATHWAY GJ, VEGA-AVELAIRA D, FITZGERALD M: A critical period in the supraspinal control of pain: opioiddependent changes in brainstem rostroventral medulla function in preadolescence. Pain 153: 775-783, 2012.

HIRSCH C, HOFFMANN J, TÜRP JC: Are temporomandibular disorder symptoms and diagnoses associated with pubertal development in adolescents? An epidemiological study. J Orofac Orthop 73: 6-8, 2012.

HOPCHET L, KULO A, RAYYAN M, VERBESSELT R, VANHOLE C, DE HOON JN, ALLEGAERT K: Does intravenous paracetamol administration affect body temperature in neonates? Arch Dis Child 96: 301-304, 2011.

HOUFFLIN DEBARGE V, BRESSON S, JAILLARD S, ELBAZ F, RIOU Y, DALMAS S, DERUELLE P, DUCLOY AS, PUECH F, STORME L: Development of a new model to investigate the fetal nociceptive pathways. Fetal Diagn Ther 20: 415-419, 2005.

HOWARD RF, WALKER SM, MOTA PM, FITZGERALD M: The ontogeny of neuropathic pain: postnatal onset of mechanical allodynia in rat spared nerve injury (SNI) and chronic constriction injury (CCI) models. Pain 115: 382-389, 2005.

HOZA J: Pain in children (in Czech). Remedia 1-2: 49-52, 1995.

ISLAM AK, COOPER ML, BODNAR RJ: Interactions among aging, gender, and gonadectomy effects upon morphine antinociception in rats. Physiol Behav 54: 45-53, 1993.

JOHNSON CC, STEVENS B, CRAIG KD, GRUNAU RV: Developmental changes in pain expression in premature, full-term, two- and four-month-old infants. Pain 52: 201-208, 1993.

JOHNSON R, SPENCE S: Pain, affect, and cognition in children: 2. Recall bias associated with pain. Proc 7th World Congress on Pain, 1994, pp 877-884.

JOHNSON R, SPENCE SH, CHAMPION GD, ZIEGLER JB: Pain, affect, and cognition in children: 1. The influence of affective state on pain in children. Proc 7th World Congress on Pain, 1994, pp 869-875.

JOHNSRUD ML, DALE PO, LØVLAND B: Benefits of continuous infusion epidural analgesia throughout vaginal delivery. Acta Obstet Gynecol Scand 67: 355-358, 1988.

JOSEPH EK, GEAR RW, LEVINE JD: Mechanical stimulation enhances endothelin-1 hyperalgesia. Neuroscience 178: 189-195, 2011.

KOCH SC, FITZGERALD M, HATHWAY GJ: Midazolam potentiates nociceptive behavior, sensitizes cutaneous reflexes, and is devoid of sedative action in neonatal rats. Anesthesiology 108: 122-129, 2008. 
KRAKOWSKI L, GESTIN Y, JAULMES F, LAKDJA F, MEYNADIER J, POULAIN P, POZZO DI BORGO C, REBATTU P, SCHACH R, GOLDBERG J, BOUREAU F, FALCOFF H, GUILLAIN H, LARUE F, MAGNET M, SALAMAGNE M, SERRIE A, TREEHOT P, VERDIE JC: Recommandations pour une bonne pratique dans la prise en charge de la douleur du cancer chez l'adulte et l'enfant. Bull Cancer 83 (Suppl 1): 1-84, 1996.

KUBO A, KOYAMA M, TAMURA R, TAKAGISHI Y, MURASE S, MIZUMURA K: Absence of mechanical hyperalgesia after exercise (delayed onset muscle soreness) in neonatally capsaicin-treated rats. Neurosci Res 73: 56-60, 2012.

LESTER BM, MILLER RJ, HAWES K, SALISBURY A, BIGSBY R, SULLIVAN MC, PADBURY JF: Infant neurobehavioral development. Semin Perinatol 35: 8-19, 2011.

LEWIN GR, MENDELL LM: Regulation of cutaneous C-fiber heat nociceptors by nerve growth factor in the developing rat. J Neurophysiol 71: 941-949, 1994.

LIMA PV, KRAMER PF, IOPPI L, HOFFMANN R DA R: Temporomandibular joint ankylosis surgery in a child: case report. J Dent Child (Chic) 78: 102-106, 2011.

MARSH D, DICKENSON A, HATCH D, FITZGERALD M: Epidural opioid analgesia in infant rats. II: Responses to carrageenan and capsaicin. Pain 82: 33-38, 1999.

MCGRATH PJ, UNRUH AM: Measurement and assessment of paediatric pain. In: Wall and Melzack's Textbook of Pain. SB MCMAHON, M KOLTZENBURG (eds), Elsevier, Churchill Livingstone, 2006, pp 305-315.

MCGRAW MB: Neural maturation as exemplified in the changing of the infant to pinprick. Child Dev 12: 31-42, 1941.

MELZACK R, WALL PD: Pain mechanisms: a new theory. Science 150: 971-979, 1965.

MOHAMAD O, CHEN D, ZHANG L, HOFMANN C, WEI L, YU SP: Erythropoietin reduces neuronal cell death and hyperalgesia induced by peripheral inflammatory pain in neonatal rats. Mol Pain 7: 51, 2011.

MOSS A, BEGGS S, VEGA-AVELAIRA D, COSTIGAN M, HATHWAY GJ, SALTER MW, FITZGERALD M: Spinal microglia and neuropathic pain in young rats Pain 128: 215-224, 2007.

MYSLIVEČEK J, HASSMANNOVÁ J, ROKYTA R, SOBOTKA P, ZÁHLAVA J: Peculiarities on influencing cortical synapses at early periods of postnatal live. Macroelectrode recordings. Plzen̆ Lek Sborn 25: 9-34, 1965.

NEISEWANDER JL, NONNEMAN AJ, ROWLETT JK, BARDO MT: Impaired supersensitivity to morphine following chronic naltrexone treatment in senescent rats. Neurobiol Aging 15: 91-97, 1994.

OWENS ME: Pain in infancy: conceptual and methodological issues. Pain 20: 213-230, 1984.

PUJOL A, DE CABO C, MARTIN MI, VIVEROS MP: A developmental study on stress-induced antinociception measured by the tail electric stimulation test. Pharmacol Biochem Behav 46: 373-376, 1993.

RAJEVSKÁ O, HRABĚTOVÁ S, ROKYTA R: The developmental changes of rat's nociception by different kind of pain stimuli. J Physiol Biochim Biophys 99: A159, 1990.

ROKYTA R: Pain - morphological and physiological backgrounds (in Czech). Remedia 1-2: 64-70, 1995.

ROKYTA R, HASSMANNOVÁ J, MYSLIVEČEK J, ZÁHLAVA J: The peculiarities of the synaptic transmission in the brain during postnatal development (in Czech). Čs fyziol 12: 333, 1963.

ROKYTA R, KRŠIAK M, KOZÁK J: Bolest (Pain) (in Czech), Tigis, Prague, 2006.

ROSSITCH E JR, LYERLY MA, OVELMEN-LEVITT J, YOUNG JN, NASHOLD BS JR: Deafferentation syndrome in the rat: effects of sex, age, and lesion type. Surg Neurol 37: 89-93, 1992.

SANCHEZ-SIMON FM, ARENZANA FJ, RODRIGUEZ RE: In vivo effects of morphine on neuronal fate and opioid receptor expression in zebrafish embryos. Eur J Neurosci 32: 550-559, 2010.

SHERMAN M, SHERMAN IC: Sensorimotor responses in infants. Psychology 5: 53-68, 1925.

SHOAE-HASSANI A, SHARIF S, TABATABAEI SA, VERDI J: Could the endogenous opioid, morphine, prevent neural stem cell proliferation? Med Hypotheses 76: 225-229, 2011.

SLATER R, CORNELISSEN L, FABRIZI L, PATTEN D, YOXEN J, WORLEY A, BOYD S, MEEK J, FITZGERALD M: Oral sucrose as an analgesic drug for procedural pain in newborn infants: a randomised controlled trial. Lancet 37: 1225-1232, 2010.

TANCK EN, KROIN JS, MCCARTHY RJ, PERM RD, IVANKOVICH AD: Effects of age and size on development of allodynia in a chronic pain model produced by sciatic nerve ligation in rats. Pain 51: 313-316, 1992. 
TSENG LF, COLLINS KA, WANG Q: Differential ontogenesis of thermal and mechanical antinociception induced by morphine and beta-endorphin. Eur J Pharmacol 277: 71-76, 1995.

UNRUH AM: Voices from the past: ancient views of pain childhood. Clin J Pain 8: 247-254, 1992.

VEGA-AVELAIRA D, MOSS A, FITZGERALD M: Age-related changes in the spinal cord microglial and astrocytic response profile to nerve injury Brain Behav Immunol 21: 617-623, 2007.

VIVEROS MP, PUJOL A, DE CABO C, MARTIN MI: A study on the development of nociceptive responses in preand postweaning rats: the tail electric stimulation test as a suitable methodology. Exp Clin Pharmacol 15: 3133, 1993.

WALKER SM, FRANCK LS, FITZGERALD M, MYLES J, STOCKS J, MARLOW N: Long-term impact of neonatal intensive care and surgery on somatosensory perception in children born extremely preterm. Pain 141: 79-87, 2009a.

WALKER SM, TOCHIKI KK, FITZGERALD M: Hindpaw incision in early life increases the hyperalgesic response to repeat surgical injury: Critical period and dependence on initial afferent activity. Pain 147: 99-106, $2009 \mathrm{~b}$.

WASZ-HOCKERT O, LIND J, VUORENKOSKI V: The infant cry: a spectrographic and auditory analysis. Clinics Dev Med 6: 9-42, 1968.

WASZ-HOCKERT O, MICHELSSON K, LIND J: Twenty-five years of Scandinavian cry research. In: Infant Crying: Theoretical and Research Perspectives. BM LESTER, C BOUKYDIS (eds), Plenum Press, New York, 1985 , pp 83-104.

WILLIAMS DG, DICKENSON A, FITZGERALD M, HOWARD RF: Developmental regulation of codeine analgesia in the rat. Anesthesiology 100: 92-97, 2004.

WILLIAMSON PS, WILLIAMSON ML: Physiologic stress reduction by a local anesthetic during newborn circumcision. Pediatrics 6: 36-40, 1983.

YASTER M: Multimodal analgesia in children. Eur J Anaesthesiol 27: 851-857, 2010.

YOUNG WK, D'HEMECOURT PA: Back pain in adolescent athletes. Phys Sportsmed 39: 80-89, 2011.

ZBUZEK VK, CHIN CW: Prenatal nicotine exposure increased duration of nicotine-induced analgesia in adult rats. Psychopharmacology (Berl) 113: 434-438, 1994. 